\title{
Limitations of the Western Scientific Worldview for the Study of Metaphysically Inclusive Peoples
}

\author{
Gerhard P. Shipley1, Deborah H. Williams ${ }^{2,3}$ \\ ${ }^{1}$ University of Kansas, Lawrence, KS, USA \\ ${ }^{2}$ Department of Anthropology, University of Kansas, Lawrence, KS, USA \\ ${ }^{3}$ Department of Environmental Science, Johnson County Community College, Overland Park, KS, USA \\ Email: Research_Studies@outlook.com
}

How to cite this paper: Shipley, G. P., \& Williams, D. H. (2019). Limitations of the Western Scientific Worldview for the Study of Metaphysically Inclusive Peoples. Open Journal of Philosophy, 9, 295-317. https://doi.org/10.4236/ojpp.2019.93020

Received: June 21, 2019

Accepted: August 5, 2019

Published: August 8, 2019

Copyright ( 2019 by author(s) and Scientific Research Publishing Inc. This work is licensed under the Creative Commons Attribution International License (CC BY 4.0).

http://creativecommons.org/licenses/by/4.0/

(c) (i) Open Access

\begin{abstract}
The study and understanding of peoples whose worldviews include metaphysical phenomena and explanations are undermined by the strict adherence of many social scientists to the Western scientific worldview which acknowledges only physical phenomena and explanations. The effect of employing Western science in studying the material and practiced cultures of these peoples is to reduce them to constituent ontological components, strip away and discard their metaphysical aspects, and then take what can be readily extracted while leaving what is not understood and therefore not valued. This disrespects the knowledge and alternative worldviews of the very peoples that social scientists seek to more fully understand. One solution is not only to acknowledge the existence of and study alternative worldviews, but also to include and even operationally adopt them when appropriate or necessary to more fully appreciate the metaphysical perspectives of other cultures. In anthropology, for example, this approach could be accomplished by extending the rationale for and methodology of participant observation to include worldview pluralism, and employing the most appropriate worldview for a subject or aspect of a subject under study. In archaeology, this approach is consistent with the goals of the growing Indigenous archaeology movement. Specifically, if the subject has a metaphysical aspect, then a non-Western scientific worldview should be employed in studying that aspect rather than simply dismissing it as unimportant or even non-existent. This paper summarizes the philosophical framework underlying Western science and the evolution and current state of the Western scientific worldview in the social sciences, compares and contrasts Western science with Indigenous peoples' way of knowing, and presents an example of how the limits of the Western
\end{abstract}


scientific worldview can negatively impact the study of metaphysically inclusive peoples.

\section{Keywords}

Western Scientific Worldview, Social Science, Indigenous Worldview, Indigenous Peoples, Sacred Bundle, Indigenous Archaeology

\section{Introduction}

"Wrong thinking in the natural sciences is lamentable but, sooner or later, will be rejected. Wrong thinking in the social sciences may escape this fate; thus it is not merely lamentable but dangerous" (Feldhammer, 1967: p. 29).

The word "science" carries great authority in Western society (Ryan, 2011; Turnbull, 2000), and "only through the use (and praise) of the 'scientific method' [can] any study put forth a claim to intellectual legitimacy" (Feldhammer, 1967, pp. 29-30). The Western scientific worldview has become "a locus of cultural power" (Marks, 2009: pp. x-xi), and its influence is so pervasive that "even the most liberal universities operate in ways that place substantial domains of human experience, thought, and insight outside the conventional bounds of legitimate knowledge" (Howitt \& Suchet-Pearson, 2003: p. 557). As a result, it now largely controls what is learned, what is funded, what is studied, how it is studied, and what is published (Barth, 2002; Berkes, 2012; Marks, 2009). Seeking greater legitimacy, the social sciences adopted the Western scientific worldview and are attempting, with varying success, to align themselves with Western science through radical, uncompromising scientism (Feldhammer, 1967).

However, the study and understanding of peoples whose worldviews include metaphysical phenomena and explanations is undermined by many social scientists' strict adherence to the Western scientific worldview which acknowledges only physical phenomena and explanations. In anthropology and archaeology, for example, it has negatively impacted the study of those Native American and other Indigenous peoples whose knowledge traditions and worldviews make few or no distinctions between or at least inextricably link the physical world and the metaphysical world. Most importantly, it devalues and disrespects the knowledge and alternative worldviews of the very peoples that social scientists are attempting to more fully understand.

Marks (2009), a professor of anthropology, revealed this tension when he titled his book Why I am Not a Scientist but then immediately admitted that he is, in fact, a scientist, at least insofar as he treated the natural and the supernatural (which he equated with the spiritual) realms as disconnected from one another (Marks, 2009). Marks went on to criticize the Western scientific worldview's position that "all other knowledge, and all other forms of knowledge production, are illegitimate" (Marks, 2009: p. x), but never reconciled his dis- 
connection of the physical from the metaphysical with his call to respect other ways of knowing that make no such disconnection. Olafson (2001) also revealed this tension by arguing that the limits of naturalism were unnecessary and detrimental to all science, while expressly rejecting metaphysical phenomenon and explanations and retaining the criterion of empirical verifiability.

For this paper, we briefly summarize the philosophical framework underlying Western science, summarize the evolution of the Western scientific worldview in the social sciences, compare and contrast Western science with the Indigenous way of knowing, and present an example of how the Western scientific worldview negatively impacts the study of peoples with alternative worldviews. In doing so, we seek to make at least three contributions to the discourse on this issue. First, the issue is multidisciplinary and requires a thorough grounding in philosophy, science, social science, and Indigenous studies. Many of those who have written on this issue have formal training in one or two of these areas and understand the others only through the paradigms of their primary disciplines. For example, geographers' preference for characterizing ways of knowing and knowledge in terms of "space" (e.g., "knowledge spaces")," "place," and "position" (Johnson \& Murton, 2007; Turnbull, 2000) while valid and interesting, would not be easily recognized by many Western philosophers and scientists who, not trained or inclined to think in those terms, might find it distracting. We have formal graduate education in all of these disciplines and so can provide a truly multi-disciplinary perspective without provoking unnecessary digressions resulting from esoteric terms and perspectives.

Second, the issue can be approached through many different dichotomies, including the culture versus nature ontological dichotomy discussed by, e.g., Descola (2013), the assembled heterogenous local knowledge (of Western technoscientists) versus non-assembled heterogenous local knowledge (of Indigenous peoples) dichotomy discussed by Turnbull (2000), the racialized "Red" versus "White" dichotomy invoked by Deloria (1997), and many others (e.g., literate versus oral, modern versus traditional, subject versus object, open versus closed). This paper approaches the issue in terms of the Western scientific worldview being metaphysically exclusive and the Indigenous worldview being metaphysically inclusive, i.e., the former does not recognize metaphysical phenomena and explanations and the latter does. This particular dichotomy is occasionally referenced (by, e.g., Johnson \& Murton (2007)) but rarely focused upon.

Third, the nature and importance of the issue can by illustrated by many different examples. Again, many of those who have written on this issue select examples that reflect the interests and perspectives of their primary disciplines or that present the issue abstractly (such as Turnbull's (2000) example involving gothic cathedrals), which, while valid and interesting, may not be easily appreciated by readers from other disciplines. This paper includes an example of actual anthropological research in which the Western scientific worldview approach of the researchers had a clearly negative impact. 


\section{Western Science and the Western Scientific Worldview}

Worldviews are how we represent and understand our place in and relationships with the world, which includes our values, attitudes, and beliefs (Ryan, 2008). The meanings we make from our interactions with one another and the world are shaped by our worldviews and become our knowledge (Ryan, 2008). Worldviews are often characterized by their subjective content, and because science is believed to be objective (and secular) it is often not thought of as having any worldview content (Irzik \& Nola, 2009). However, worldviews are much more broadly concerned with interpreting and interacting with the world on all levels of human experience, and "are characterized by their generality and their tendency to be comprehensive" (Irzik \& Nola 2009: p. 730). Of particular relevance to this paper, worldview content broadly includes the kinds of questions that are asked, the methodology that is used to answer them, and the acceptability of the answers.

More than a brief summary of the philosophical foundation of Western science and the Western scientific worldview is beyond the scope of this paper and is widely available. However, it is necessary to identify at least some of the philosophical assumptions made by Western science in order to appreciate that, contrary to the belief of many scientists, it is not objective, universal, or acultural. These include 1) "realism," or "objectivism," which is the ontological assumption that an objective reality exists independent of our minds; 2) "empiricism," which is the epistemological assumption that at least some of the aspects of that objective reality can be observed and measured; 3) "positivism," which is the even stronger epistemological assumption that knowledge that is not derived from the scientific method is not objective and therefore cannot be validated, and 4) "inductivism," which is the further epistemological assumption that global propositions (i.e., theories) can be derived from local observations. Further, many scientists subscribe to radical positivism, or "scientism," which asserts that phenomena that do not meet the philosophical assumptions of Western science are simply not real.

Within each of these positions are even more secondary assumptions. For example, Western science is built on the notion of progress in understanding, and in order to judge progress we must be able to assess the degree to which our beliefs are justified and know how to create better-justified beliefs (Chang, 2007). In that light, "foundationalism" asserts that if we create a firm foundation of strongly justified prior knowledge, then scientific progress is simply a matter of building on that foundation. This approach is problematic because the aforementioned and other assumptions undermine the completeness of observations and conclusions such that justification becomes increasingly tenuous as we build and scientific knowledge becomes a house of cards. "Coherentism" asserts that the only available justification for a belief is that it coheres with our other beliefs. This approach is also problematic because it leads to a form of relativism in which multiple internally-coherent explanations can exist for the same pheno- 
menon. Other assumptions underlying the scientific method include the principle of causality which assumes that cause must precede effect (which is necessary for experimental reproducibility), and the principle of parsimony which asserts that, ceteris parabis, the simplest solution is preferred (wherein this introduction of preference clearly reveals this to be a value judgment in direct conflict with science's claim to eschew such judgments) (Tauber, 2009). Many argue that we live in post-positivist times, and yet clearly physical scientists and many social scientists are still very much invested in and following a positivist paradigm. Importantly, for each of the positions favored by the Western scientific worldview, there is at least one alternative position which may be favored by other peoples with alternative worldviews.

Many Westerners view science and philosophy as "non-overlapping magisterial" (Gould, 1997), which is exacerbated by an outdated academic paradigm that largely isolates them from and treats them as irrelevant to each other. It is only because they know so little about the philosophical foundation for and evolution of the Western scientific worldview (Tauber, 2009, citing Kuhn, 1962) that many scientists dismiss philosophy as irrelevant to their endeavors. "Part of the arrogance of Western science has been that it sets itself within a hall of mirrors...mistakes its reflection for the world, sees its own reflections endlessly, talks endlessly to itself, and, not surprisingly, finds continual verification of itself and its worldview" (Rose, 1999: p. 177). Ideally, social scientists "need to break free of this 'hall of mirrors' and affirm the existence and value of other knowledge systems" (Johnson, 2012: p. 835).

"[Western] science should be properly privileged only within its own domain, namely the construction of a naturalistic understanding of natural phenomena" (El-Hani \& Bandeira, 2008: p. 755). There is nothing inherently wrong with the Western scientific worldview is so long as Western scientists understand that their assumptions could be incomplete or incorrect, their research reflects their assumptions, and, in particular, the Western scientific approach reflects a particular worldview rather than a neutral perspective independent of any particular culture. However, the Western scientific worldview can be especially problematic for the social sciences because privileging the Western scientific perspective, especially when studying Indigenous peoples, is far too limiting and, further, is arguably a manifestation of cultural evolutionism and the notion of Western culture and science being inherently superior to non-Western cultures and ways of knowing.

\subsection{Scientism in the Social Sciences}

In general, the physical sciences seem satisfied to stop with the minimum number of necessary philosophical assumptions and adopt an agnostic view toward phenomena and explanations that do not meet them and therefore fall outside of the purviews of those disciplines. However, the social sciences seem to increasingly lean toward scientism and outright reject the existence of such phenome- 
na and explanations. Under this view, knowledge is real only if it is amenable to empirical verification, and, as such, metaphysical questions and explanations are meaningless and metaphysical phenomena do not exist. Scientism requires radical "reductionism" which involves translating phenomena and explanations into methodologically acceptable input by reducing them to components that are amenable to study by the scientific method. To a follower of scientism, nothing is lost in this process because the phenomenological and explanatory components that cannot be translated and are therefore lost are nonsense. Of course, this reductionistic approach is especially problematic for anthropologists, archaeologists, and other social scientists because it undermines their ability to fully study and appreciate some of the most fundamental aspects of their research subjects.

Auguste Comte, the founder of the discipline of sociology, founded it as a positivist endeavor and "explicitly presented the scientific method as the supreme guide to knowledge, and science as the most important of human activities" (Morganti, 2013: p. 2). Comte created an account of social evolution in which societies that emphasize spiritual explanations are at the lowest stage, and societies that emphasize scientific explanations are at the highest (Morganti, 2013). Although modern social scientists say they have disclaimed Comte's hierarchical socio-evolutionary scheme, the underlying bias is still reflected in the research questions they ask, the research methodologies they use, and their treatment of knowledge based in other ways of knowing. Feldhammer (1967) acknowledged that the discipline of anthropology sought to legitimize itself and become a respectable member of the scientific establishment by making man's social behavior into a proper subject for scientific inquiry (Feldhammer, 1967). This involved "a general adoption of certain prevailing assumptions whose theoretical and practical effects have now-and for a long time past-been an obstacle to further understanding" due to the "dominance of naturalism, objective empiricism, and 'scientism' prevalent among social anthropologist” (Feldhammer, 1967: pp. 29-31).

Only three decades ago, O'Meara (1989: p. 354) reported that “more and more anthropologists are rejecting the empirical basis, logical methods, and explanatory goals of the so-called 'natural sciences' as being inappropriate for the study of human affairs... [and] some anthropologists argue that we must abandon empirical science and turn instead to the humanities for guidance." However, in response to criticism, O’Meara (1990: p. 751) quickly backtracked and affirmed that "anthropological approaches that eschew empirical science are not therefore humanistic... they are metaphysic," and as metaphysical statements cannot be tested empirically they cannot be refuted, so only as empirical science can anthropology be humanistic. Further, despite the shift initially reported by O'Meara, just two decades ago Pulido (1998: p. 719) succinctly confirmed that scientism was alive and well in the social sciences:

How do we as social scientists treat the spiritual beliefs of those who are the 
focus of our research?... To date, I believe that [we] have been largely dismissive of the spirituality of the people we study...Indeed, in our quest to be scientists, we have done our best to ignore this central part of the human experience... There are many reasons why social scientists distance themselves from spirituality. Most obviously, we are supposed to be concerned with 'the facts': Gathering and analyzing supposedly objective, empirical, and measurable data...as we privilege materialism and dismiss [the metaphysical].

Nicholas (2001: p. 34, emphasis added) also confirmed it: "In Western culture, the basis of knowledge is science. And science, in turn, is derived from positivism...It is an empirically based system of knowledge... Both anthropology and archaeology are firmly anchored in positivism." Barth (2002) proposed a framework of disaggregation, dissection, and analysis for a comparative ethnography of knowledge, which includes being meticulous in recording how items of knowledge are a part of specific practices. But when Barth described the Baktaman's (of New Guinea) understanding of growth (of, e.g., leaves, hair, fur, fat) as an effect of an invisible force, he characterized it "as cumulative and harmonizing metaphors" (Barth, 2002: pp. 4-5). Thus, in actual practice, Barth characterized metaphysical explanations as mere "metaphors" rather than real explanations, which is consistent with the Western scientific worldview. Less than a decade ago, Fabian (2012) noted that the while humanism and scientism is still debated in anthropology, "the struggle for liberation from positivism and scientism never meant that empirical accountability and claims to the scientific status of our findings were to be abandoned" (Fabian, 2012: p. 441). In fact, Western science is often treated by anthropologists as if it were beyond question or analysis (Mendin \& Bang, 2014, citing Nader, 1996; Olafson, 2001):

For much of the twentieth century, research approaches and procedures in social science were rooted in the positivist paradigm, which is concerned with investigating phenomena that are de-contextualized, observable, and measured using objective methods within the quantitative approach. This restricts the possibility of gaining knowledge of what can be known using other research worldviews, paradigms, and approaches that include constructivist, qualitative approach, participatory research paradigm, and Indigenous-based [ways of knowing]. Knowledge through the positivist paradigm is, therefore, none other than the result of Western-based science that is associated with its ontological, epistemological, axiological, methodological and rhetorical assumptions (Goduka, 2012: p. 123).

Certainly, "a few anthropologists have also begun to realize the importance of emplacing Indigenous knowledge within their research" (Johnson \& Murton, 2007: p. 127) but "anthropology—or at least large segments of it-is self-consciously 'science”" (Marks, 2009: pp. xi-xii). While "orthodox analysts of science, including historians and philosophers, are starting to change their minds about 
the origins, nature, and status of science" (Turnbull, 2000: p. 5), this evolution of thought in the humanities has not affected the work of the majority of scientists or social scientists. Even in the field of the sociology of scientific knowledge (SSK), which seeks to deconstruct and examine science and technology, there has been "limited success in changing the broader community understanding" (Turnbull, 2000: pp. 4-5). "[SSK] is also awash in claims that it has reached maturity, has proven sterile, is an attack on civilization as we know it, ... like all forms of constructivism and relativism is self-contradictory and therefore just more postmodern claptrap... SSK is under attack from without and within and has almost as many variants and theoretical orientations as there are proponents" (Marks, 2009: p. 216).

The common misunderstanding among Western scientists that science is intrinsically acultural and value-free (Cajete, 2000; Mendin \& Bang, 2014) may be, at least in part, a protective reaction stemming from historical attempts to co-opt science, especially social science, into the service of various social movements and ideologies, including colonial agendas (e.g., the so-called "scientific racism" of the nineteenth and twentieth centuries). However, the production of knowledge can never be wholly objective or neutral, but rather unavoidably reflects the ignorances, biases, and interests of the people, institutions, and societies that fund, create, and reward it. Science is a human endeavor, and therefore can only ever be as objective as the human scientists who perform it (Pierotti, 2011; Turnbull, 2000). Western science does not decontextualize knowledge and arrive at the truth, but rather all it really does is contextualize or, in the case of studying Indigenous peoples, recontextualize it and arrive at a truth (Descola, 2013). As such, Western science should be recognized for and treated as what it is: Western "ethnoscience" (Mendin \& Bang, 2014: p. 15). In fact, "the very idea of the Scientific Revolution may someday come to be rejected as ethnocentric,' as may the very idea of 'Western science'" (Mendin \& Bang, 2014: p. 21, quoting Hess, 1995: p. 67).

The anthropological research methodology of "participant observation" recognizes the inherent weakness of studying systems from the outside (the etic approach) rather than from the inside (the emic approach), but participant observation has largely been applied only to ethnographic research, and even then it has suffered from conflicted attempts to make it as science-like as possible. Anthropologists can experience a great deal of tension in attempting to comport to the Western scientific worldview and its requirement for objectivity while also recognizing the limits of Western science and attempting to achieve the level of immersed subjectivity necessary to more fully understand other cultures (Goduka, 2012). Archaeology is particularly handicapped in this regard in that "[it] is the only discipline that seeks to study human behavior and thought without having any direct contact with either. Instead archaeologists must infer what they seek to study from the material remains of the past" (Trigger, 1998: p. 1). Although the philosophical implications of their field and methodology are 
centrally important to their discipline, most archaeologists have neither the time nor the specialized training to understand them (Trigger, 1998). As a result, many scientists are content to allow a few individuals with the time and inclination do the necessary intellectual work and then rely on their conclusions. For example, the busy archaeologist might be tempted to rely on Trigger (1998), who asserted that "a realist epistemology, combined with a materialist view of reality, offers the most satisfactory general framework for...interpreting archaeological data" (Trigger, 1998: p. 1). However, that position is nothing more than Western science as it currently stands, with its inability to fully study the artifacts and practices of peoples with metaphysically inclusive worldviews.

\subsection{Western Science as a Colonial Endeavor}

Western science is not only the hallmark of the Western scientific worldview, it has the power to produce that worldview in others. "Worldview refers not only to the picture of reality science bestows, but also to the manner in which scientific thinking profoundly affects the way one perceives the world and oneself, individually" (Tauber, 2009: p. 38). When Indigenous children are taught to view the world through the lens of Western science, their worldview changes. As such, Western science education is often introduced as part of a program of human development. However, this is arguably nothing more than a form of neocolonialism - "the destructive cultural invasion of a society thought to be inferior to the invaders' society"-involving "the imposition of the invaders' worldview on the invaded culture, perpetrated by those who have a disregard for the people of the invaded culture" (Ryan, 2008: pp. 673-674). Basalla (1967) described a three-stage model historically used to inculcate Western science into a non-scientific region: 1) The region becomes a focus of Western scientific study, 2) the region becomes the focus of "colonial science" (i.e., Western scientific study performed by residents of the region trained elsewhere in Western scientific methods), and 3) the region struggles to achieve an independent Western scientific tradition or culture (i.e., to produce its own scientists trained in the Western scientific method at its own institutions) (Basalla, 1967). Importantly, the third stage does not involve retaining the Indigenous way of knowing along with the introduced Western science, but rather involves eradicating resistance to Western science based on philosophical or spiritual beliefs (Basalla, 1967). "As European settlers colonized North America...European knowledge and ways of learning were imposed through oppressive institutions such as residential schools. Indigenous ways of learning were negated and diminished, as were Indigenous knowledges" (Munroe, Borden, Orr, Toney, \& Meader, 2013: pp. 319-320). "Science education can be seen to play a part in this cultural invasion when it is represented as being a monolithic authority based on claims of universality...From the universalist position there is an assumption of authority of Western 'truths' over other cultural ways of knowing and understanding. This leads to censoring any understandings outside of the Western worldview" (Ryan, 
2008: p. 674). Importantly, if Western science were truly acultural, then, its imposition on and adoption by Indigenous peoples would have no effect on other aspects of their cultures, and yet it clearly does. As a result:

In response to what many see as Western academic oppression of Native American communities in the name of science, Indigenous researchers and community partners are increasingly calling for research to be decolonized. Decolonizing research is a process for conducting research with Indigenous communities that places Indigenous voices and epistemologies in the center of the research process. It critically examines the underlying assumptions that inform the research and challenges the widely accepted belief that Western methods and ways of knowing are the only objective, true science. Holding Western beliefs and methods as 'the' true science marginalizes Indigenous methods and ways of knowing by denigrating them as folklore or myth (Simonds \& Christopher, 2013: p. 2185).

\section{The Indigenous Way of Knowing and the Indigenous Worldview}

As with many aspects of Indigeneity, characterizations of the Indigenous worldview are evolving under political and social influences that often seem to seek to sharply distinguish the Indigenous "good" from the Western "bad." For example, Chigeza (2007) characterized Western science as "aggressive" and "manipulative" and the Indigenous way of knowing as "gentle" and "accommodating," without any discussion of what such value-laden terms mean in this context (Chigeza, 2007, citing Aikenhead, 1998). To be clear, the point of this paper is not to present the Western scientific worldview as "bad" but rather merely as limited and poorly suited for studying at least certain aspects of Indigenous cultures. Further, because knowledge production is culturally constructed, and Indigenous peoples are culturally diverse, different Indigenous peoples may have different ways of knowing and worldviews. For this paper, however, the Indigenous worldview is broadly defined by commonalities rather than differences:

[The Indigenous way of knowing] is a metaphor for a wide range of tribal processes of perceiving, thinking, acting, and "coming to know" that have evolved through human experience with the natural world. [It] is born of a life of storied participation with the natural landscape. To gain a sense of [it], one must participate with the natural world. To understand [it], one must become open to the roles of sensation, perception, imagination, emotion, symbols, and spirit as well as that of concept, logic, and rational empiricism...[The Indigenous way of knowing] is based on "perceptual phenomenology" (Cajete, 2000: p. 2).

Johnson \& Murton (2007) similarly noted a commonality among Indigenous ways of knowing involving the recognition of metaphysical aspects of reality and the connection of the spiritual, moral, scientific, and natural worlds. 
The Indigenous way of knowing is based on different philosophical assumptions which create a worldview that is holistic and interconnected (Munroe, Borden, Orr, Toney, \& Meader, 2013; Pierotti, 2011) and does not distinguish or, at least, does not discriminate between the physical and the metaphysical, or between religion, philosophy, and science (Berkes, 2012; Cajete, 2000; Pierotti, 2011; Tsosie, 2015). In fact, "the division of...the physical universe from the metaphysical one, has been unfamiliar to most people over most of the course of human history" (Marks, 2009: p. 5). This inclusion of a metaphysical aspect to reality has been called "Indigenous realism" (Wildcat, 2009). "To [Indigenous peoples], the world is composed of both spirit and matter," and it is the absence of the sacred that constitutes the gulf between the Western scientific and Indigenous worldviews (White Deer, 1998: p. 331). "The dualisms or dichotomies between the spiritual and material, culture and nature, subjective and objective, sacred and profane that operate so deeply in the Western scientific worldview appear largely absent from [the Indigenous worldview]...Indigenous traditions recognize the sacred in a world simultaneously spiritual and physical" (McGregor, 2012: p. 58). Thus, in addition to long-term, systematic, science-like empirical observations of local conditions, Indigenous knowledge is also gained through, e.g., visions, ceremonies, prayers, intuitions, and dreams (McGregor, 2012). Importantly, spiritual causes are not seen as supernatural but rather as natural and therefore subject to interpretation and understanding (Pierotti, 2011). In the Indigenous worldview, the physical and the metaphysical are aspects of a single magisterium or, at least, of largely overlapping magisteria acting simultaneously and inextricably in all things. For example, in the Indigenous worldview, time is circular rather than linear, so the past, present, and future are linked in a continuous cycle. Because time is circular, long-deceased ancestors are not increasingly temporally distant but are considered continuing members of modern groups and still inhabiting the places where they lived and left material remains and stories on the landscape (Steeves, 2015). This acknowledgment of and respect for the spiritual foundation of the world is what many Western scientists find so problematic with the Indigenous way of knowing (Wildcat, 2009).

"[The Indigenous way of knowing has] frequently been portrayed as closed, pragmatic, utilitarian, value laden, indexical, context dependent, and so on; all of which was held to imply that they cannot have the same authority and credibility as science... Science by contrast was held to be...in some mysterious way, above culture" (Turnbull, 2000: p. 41). From the Indigenous perspective, the objective, value-free scientist who discovers universal truth about an independent reality does not and cannot exist (Deloria, 1997; Goduka, 2012). Instead, the Indigenous way of knowing is both constructivistic and contextualistic (Goduka, 2012: p. 125). It is constructivistic in asserting that reality is locally and actively constructed and therefore variable between groups and not universal, and it is also socially constructed and therefore neither personal nor technical (Goduka, 
2012). "Although perception and thinking are individual, the construction process involves other social and cultural artefacts, and therefore inevitably becomes social" (Goduka, 2012: p. 125). It is contextualistic in that it asserts that truth is relative to context, i.e., to locale, time, culture, and social place (Goduka, 2012). Thus, whereas science seeks to globalize its conclusions through the objectivity of its observations, the Indigenous way of knowing remains largely localized in its validity and reliability because of its embrace of subjectivity. In this context, objectivity refers to the notion that "the investigative agent must stand back from nature and observe, ostensibly from a view from nowhere" (Tauber, 2009: p. 37). Radical objectivity has been repeatedly rejected by showing how cultural determinants unavoidably influence scientific inquiry and interpretation (Tauber, 2009). In theory, objectivity is Western science's great strength, but in reality it cannot be achieved, and if it could be, "methodology divorced from reality can only result in conclusions having no validity" (Tauber, 2009: p. 38). Perhaps stemming from this paradigmatical disconnect between Western scientists and the world they study, Western science generally refuses to accept responsibility for how the knowledge it produces is used. In contrast, the Indigenous way of knowing recognizes reciprocal obligations throughout the natural world that affect both what and how knowledge is pursued and used (Tauber, 2009).

Like Western science, the Indigenous way of knowing generates theories about the nature of the world, which can then be tested through practical applications, and revised as needed. Indigenous knowledge emerges from careful, multi-generational observation of natural phenomenon, and involves a sophisticated appreciation and understanding of the natural world (Munroe, Borden, Orr, Toney, \& Meader, 2013; Sefadei, Hall, \& Rosenberg, 2000). Thus, Indigenous knowledge is not static, subsequent generations may revise old paradigms and create new ones (Pierotti, 2011). While the knowledge of any particular Indigenous group is largely specific to the group's territory (Pierotti, 2011), taken as a whole, Indigenous knowledge is "the collective heritage of human experience with the natural world" (Cajete, 2000: p. 3). Turnbull (2000) argued that Western science and the Indigenous way of knowing are similar in that they are both locally derived. A major difference between Western science and the Indigenous way of knowing is "not in the nature of scientific knowledge but in its greater ability to move and apply the knowledge it produces beyond the site of its production" (Turnbull, 2000: p. 39). This aggregation of otherwise mixed, incompatible, and disconnected knowledge derived from a diverse set of times, places, and circumstances involves techniques of standardization and homogenization achieved through social methods of organizing the production, transmission, and utilization of that knowledge (Turnbull, 2000).

\section{Is the Indigenous Way of Knowing "Science"?}

From the perspective of many Western scientists, "Indigenous science" is an oxymoron (El-Hani \& Bandeira, 2008; Turnbull, 2000). "While Westerners free- 
ly acknowledge the existence of Indigenous art, music, literature, drama, and political and economic systems in Indigenous cultures, they somehow fail to comprehend and appreciate Indigenous science" (Goduka, 2012: p. 134). For them, science is a Western phenomenon, and while Indigenous peoples have knowledge, it is not scientific (Cajete, 2000) because it has a metaphysical element (El-Hani \& Bandeira, 2008, citing Snively \& Corsiglia, 2001; Kidwell, 1985). Others have argued that science is simply a way of understanding the world and therefore every culture has science (Kidwell, 1985); so the Indigenous way of knowing is simply Indigenous science (Pierotti, 2011). For example, Kidwell (1985) defined Indigenous science as "the activities of [Indigenous peoples] in observing physical phenomena and attempting to explain and control them." Like Western science, the Indigenous way of knowing involves observation of physical phenomena, the desire to control those phenomena and the forces behind them, and attempts to exercise that control, though, unlike in Western science, control over those forces is often achieved by establishing personal relationships with them through ritual (Kidwell, 1985). Thus, the Indigenous way of knowing can be called "scientific" within an appropriately broad framework (Kidwell, 1985). Some have gone further and argued that Western science is a mere subset of the broader and older Indigenous science (Cajete, 2000).

However, others have argued that referring to all ways of knowing as "science" ignores important differences between them and creates a category that is encompassing beyond usefulness (Marks, 2009). Further, attempting to fit the Indigenous way of knowing within science implicitly recognizes the superiority of science and implicitly bases the legitimacy of the Indigenous way of knowing on whether or not it is accepted as science (Cobern \& Loving, 2001; El-Hani \& Bandeira, 2008). Characterizing the Indigenous way of knowing as science may seem like a way to undo its devaluation, especially given the influence and pervasiveness of scientism, but "it is this connection between 'science' and some privileged epistemic status that we should disentangle" (El-Hani \& Bandeira, 2008: p. 755). "To include other ways of knowing into a broad concept of science may contribute to their devaluation, rather than to their legitimacy. What we lose in this way is the distinctiveness of other ways of knowing... [and we] set the stage for them to be submitted to the criteria of [Western science], instead of being valued by their own merits" (El-Hani \& Bandeira, 2008: p. 757).

Broadening the definition of science to encompass every human way of producing knowledge will likely not engender respect for other ways of knowing for their own sake, validity, and legitimacy (El-Hani \& Bandeira, 2008). Instead, it will likely reinforce the "revered place" of science, subject other ways of knowing to the same standards and values of Western science (El-Hani \& Bandeira, 2008), and undermine the independence of those other ways of knowing to critique science (Cobern \& Loving, 2001). Thus, it may be better to reserve the term "science" for the way of knowing practiced by Western societies, and find another term for other ways of knowing employed by Indigenous societies 
(Cobern \& Loving, 2001). In that light, "non-scientific" refers descriptively to the absence of Western scientific criteria and not disparagingly to a lack of equal legitimacy (Basalla, 1967). "Traditional bodies of knowledge should be valued for what they are, as legitimate constructs, powerful in their own domains, valid according to epistemic criteria built in their own cultural backgrounds" (El-Hani \& Bandeira, 2008: p. 763). Such a pluralist view of ways of knowing need not lead to relativism so long as the distinctions and domains of each way of knowing are respected (El-Hani \& Bandeira, 2008).

\section{An Example: Pawnee Sacred Bundles}

Historically, the Pawnee lived along tributaries of the Missouri River in central Nebraska and northern Kansas, and were among the largest groups in the Great Plains, numbering as many as ten thousand or more members (Parks, 1997). The Pawnee were semi-sedentary: In the spring, they lived in permanent dome-shaped earth lodges and planted corn, beans, and squash; during the summer, they moved into the High Plains and lived in temporary bowl-shaped shelters while hunting bison; in the late summer, they returned to their lodges to harvest, process, and store their crops; and in the winter they returned to the high plains and lived in buffalo-hide tipis while hunting bison until the spring (Good, 1989; Parks, 1997). Thus, the annual cycle of seasonal planting, hunting, harvesting, and hunting dominated Pawnee life (Wishart, 1979).

Their earth lodges were arranged so as to represent the universe, and the west side of the lodge was reserved for the sacred and included a raised altar adorned with a buffalo skull and over which was suspended the family's Sacred Bundle (Good, 1989). Whereas village Bundles derived their powers from sacred beings of the heavens, family Bundles derived their powers from sacred beings of the earth (Good, 1989). Metaphysical aspects of reality permeated Pawnee life (Good, 1989), and the Bundle scheme was the foundation on which their social and ceremonial organization rested (Good, 1989, citing Murie, 1914).

\subsection{The Physical and Metaphysical Natures of Sacred Bundles}

Physically, a Sacred Bundle is a collection of symbolic and ritual objects wrapped in buffalo hide (Parks, 1997). Because each Bundle had its origin in a different supernatural encounter, the contents of particular Bundles might vary (Good, 1989), but all contain the same types of objects (Linton, 1923). For example, one or more ears of the best specimens of the prior corn harvest were the most important addition to a Bundle because they gave it life (Good, 1989; Linton, 1923). These ears were removed in the spring and used for seed, and replaced again after the fall harvest (Good, 1989; Linton, 1923). Other common objects included pipes and extra pipe stems, braids of sweet grass, enemy scalps, pigments, tobacco, and the skins and bones of various birds and animals (Good, 1989, citing Linton, 1923, and Murie, 1981; Linton, 1923). Objects such as captured arrows or arrow fragments and pipes or pipe bowls were often attached to the outside of 
the bundle as offerings to the Bundle between its ritual openings (Good, 1989).

Metaphysically, a Sacred Bundle is a source of power to which a family or village could turn for assistance (Good, 1989). Each Bundle had its origin in a supernatural encounter in the form of a vision in which a heavenly being bestowed knowledge and power, and which was symbolized by the rituals performed when opening the Bundle (Parks, 1997). The heavenly being's gift was the explicit instructions needed to make and use the Bundle, and the objects put into the Bundle often recalled the content of the vision (Good, 1989). Every activity important to the Pawnee had its associated Bundle, including planting corn, treating the sick and injured, installing a chief, hunting, and warring (Good, 1989).

Except during ceremonial rituals, the Bundle hung from the rafters on the west side of the caretaker's lodge over the sacred altar (Good, 1989: p. 7, quoting Linton, 1923: p. 3):

When so hung, it was likened by the Pawnee to a dead man in his grave. The spirit lived in it, but slept. Even when opened, the Bundle continued asleep until the Mother-Corn had been placed in it. It then came to life, and during the ceremony the corn and other objects represented, individually and collectively, supernatural beings.

Sacred Bundles were stewarded by women, and this responsibility was inherited through the female line (Linton, 1923). However, women were not allowed to open them or to know or perform the ceremonies associated with them (Linton, 1923). "Men only opened the bundles to use and renew them ceremonially" (Good, 1989: p. 7). Furthermore, with regard to village Bundles, only a priest, not the chief in whose lodge it hung, knew its rituals and performed the ceremonies associated with it (Parks, 1997). Pawnee priests mediated between the village and the sacred beings to promote village welfare through good fortune and order (Parks, 1997). "They themselves had no power; they only knew the complex rituals and knowledge associated with each village's Sacred Bundle...” (Parks, 1997: p. x).

\subsection{Scientific Desecrations of Sacred Bundles}

Anthropologists' willingness to desecrate these Bundles in their zeal to satisfy scientific curiosity is not a new phenomenon. James R. Murie studied the Pawnee in the early twentieth century, and acquired five Sacred Bundles for the Field Museum of Natural History (Good, 1989). "All of these Bundles were opened upon their arrival at the Field Museum, and information as to the exact contents of each Bundle was not recorded in detail. At present, the contents of all Bundles are being stored together" (Good, 1989: p. 8). This behavior is sometimes referred to as "colonial science," i.e., science carried out under different standards for Indigenous peoples than for colonial peoples because of different political, economic, or social standings (Marks, 2009).

As told by Good (1989), in 1987, a Pawnee individual donated a family Sacred Bundle to the Kansas State Historical Society. The Bundle had remained un- 
opened for over a century. A condition of the donation was that the Bundle would be exhibited on the west wall of the Pawnee Indian Village Museum, near Republic, Kansas, which was constructed over the excavated floor of a Pawnee earth lodge. The path to this donation began in 1873, when the US government granted the Pawnee permission to travel to western Nebraska to hunt bison, and approximately two hundred and fifty men, one hundred women, and fifty children made the journey from their reservation in central Nebraska. The Sioux had also been granted permission to hunt bison in the same area, and on the return journey, the Pawnee, armed with bows and arrows, were attacked by approximately one thousand Sioux armed with firearms. Approximately one hundred and fifty Pawnee were killed and eleven women and children were captured. During the battle, a Pawnee man tied his young daughter to a pack horse, tied the family's Sacred Bundle to the girl's back, told her to take care of the Bundle, and sent the horse running so that the girl survived even though her parents did not. "The Bundle had existed before the massacre, but any previous history as well as any special ceremonies belonging to the Bundle were forever lost in the carnage at Massacre Canyon. According to the donor, the Bundle had not been ritually opened and is, therefore, intact as it was when it left canyon in 1873" (Good, 1989: p. 4, citing Horsechief, 1988). The bundle was cared for by female members of the family until none remained who were willing to accept the responsibility, at which time it was donated to the Society.

As further told by Good (1989), the Society's Archaeological Department photographed the Bundle, then sealed it in a plastic bag with an insecticidal strip for approximately six weeks, and then thoroughly vacuumed away accumulated dust and bug residue. The Bundle is generally cylindrical and approximately sixty-five centimeter long and twenty-four centimeters in diameter at its mid-point, the bison-hide cover was traditionally stained with red ochre, and the Bundle was secured with leather straps tied in knots. Secured to the outside of the Bundle by these straps were three arrow fragments, a wood and bone meat fork, four small American flags stapled onto wooden dowels, a stalk of plant material (probably sagebrush), and a stone pipe bowl with a wooden stem. A one-dollar bill, dated 1969, was inserted into the folds at one end of the Bundle. Because the ritual for opening the Bundle was lost, subsequent offerings (such as, possibly, the one-dollar bill) made to the Bundle were attached to its exterior.

Good (1989: p. 5, emphasis added) asked, "The donor had given permission to open the Bundle, examine the contents, and undertake necessary conservation action. But do scientists have the right to invade a sacred item such as this Bundle because of a possible need for conservation and a scientific quest for information, and should those concerns outweigh the issue of sacredness to the Pawnee and other Native American peoples?' However, having perfunctorily asked this most important question, Good provided no further discussion of the issue. Without treatment, the leather straps were too brittle to survive the process of untying the knots; however, the semi-tanned leather would also not survive tra- 
ditional leather conservation methods. Thus, it was decided to forgo physically opening the Bundle for purposes of conservation and, instead, to attempt to regulate decay by controlling the conditions of exhibition. In accordance with sound archaeological practice, "the decision to leave the Bundle unopened left options for the use of techniques which might be developed in the future to further analyze Bundles such as this through non-invasive procedures" (Good, 1989: p. 19). However, it was also decided to use currently available "non-invasive" techniques to study the Bundle's contents. The Bundle was initially subjected to $\mathrm{x}$-ray radiation to produce four sets of radiographic images of its contents, a set in each direction along its short axis, and a set in each direction along its long axis, and later also subjected to Computerized Axial Tomography (CAT) scanning to produce sixty-four images showing slices through the Bundle at one-centimeter increments. Analyses of these images indicated the presence of an inner liner which may have been either of fabric or woven grass. Other contents included bundles of reeds or sticks, a bundle of (possibly) sweet grass, (possibly) a real or simulated human scalp, animal and bird bones, bird skins, arrow fragments, beads and bells, and a pouch of (possibly) paint. "The results of the radiographic photography confirm the inclusion of some of the contents expected to be found in the Bundle" (Good, 1989: p. 19). However, the imaging failed to reveal an ear of corn. As mentioned, the ear would have been removed in the spring and planted, and then replaced in the fall after the harvest. The massacre in which this Bundle's opening ritual was lost occurred in August-after the spring planting and before the fall harvest-which may explain why it contains no corn. However, it is unclear whether this means that the Bundle is dead or simply dormant.

Importantly, little thought was given to the metaphysical aspect of the Bundle, the value of which far outweighed the value of determining the nature of its physical contents. If the Bundle could have been physically opened with less risk of damage, it likely would have. It can be argued that the "non-invasive" techniques used to image the Bundle's contents comported with the letter of the rule regarding not opening the Bundle, but it can also be argued that the researchers violated the spirit of that rule (no pun intended) and thereby desecrated the Bundle and destroyed its metaphysical value. The knowledge gained was hardly worth the risk or the likely cost. Sound archaeological practice requires that scientists forgo some of their current curiosity in order to preserve specimens for future study using better techniques, so surely it would have been better to not image the contents and wait until the Bundle simply decayed and released its contents on its own or until a time when techniques for assessing metaphysical aspects are developed. Of course, the latter possibility requires an acknowledgement that the spiritual beliefs of peoples whose cultures are under study have real meaning-an acknowledgement which the Western scientific worldview does not make.

When Western scientists used radiographic techniques to investigate the 
physical contents of the Bundle, they very arguably destroyed its metaphysical significance. Given that Western science can say nothing about an aspect of a thing that cannot be empirically investigated, Western scientists might consider this no great loss or even no loss at all. But they are mistaken: It does not follow from the inability of Western science to examine the metaphysical that the metaphysical does not exist, and conscientious researchers must at least acknowledge the possibility that it exists. To be clear, Anthropologists' need not accept for themselves the reality of metaphysical phenomena, but they should allow that such phenomena may exist and, much more importantly, must respect the fact that many of their subjects accept that they exist. "Acknowledging that an 'ontological diversity' does exist and 'taking seriously the philosophies and experiences of Indigenous groups,' is a first step toward finding a common ground upon which a dialogue between knowledge systems can take place" (Johnson, 2012: p. 833, citing Howitt \& Suchet-Pearson, 2003: p. 557). By radiographing the Bundle, scientists learned little and may have destroyed that which was much more important. As a result of this desecration, scientists were likely left not with an intact Pawnee Sacred Bundle but rather a collection of physical objects that once comprised such a Bundle and are now merely a bundle.

\section{Conclusion}

The effect of employing Western science in studying Indigenous peoples is to strip away their metaphysical aspects and reduce them to constituent components (e.g., genetics, morphology, language, subsistence strategy), take what can be quickly and easily extracted from one subject, and methodically move on to the next subject. To many Indigenous people, it is appalling "that the West can desire, extract, and claim ownership of our ways of knowing, our imagery, the things we create and produce, and then simultaneously reject the people who created and developed those ideas" (McGregor, 2003: p. 404). This strips away the subject's humanity, and it ultimately stems from an overwhelming drive to control the subject through essentialist characterization. In this sense, implicit within the Western scientific worldview may be a socio-evolutionary scheme in which the hierarchical categories of "modern" and "primitive" have been replaced by the hierarchical categories of "metaphysically exclusive" and "metaphysically inclusive," and in which the progress of peoples from darkness to enlightenment is measured in the degree of their acceptance of the Western scientific worldview.

The Western science paradigm is a way of knowing which has proven suitable for studying certain phenomenon but which has equally proven to be unsuitable for studying other phenomenon, especially certain aspects of Indigenous peoples. "In spite of the usefulness of modern scientific discoveries, there is a lot left out of Western science... 'it leaves out the sacredness, the livingness, the soul of the world. And it does get troublesome when some scientists tell us... that the part they leave out is really not there"' (Little Bear, 2000: pp. ix-x, quoting Hayward, 
1997). Anthropology and other social sciences should emphasize and work toward a more synthetic understanding of Indigenous peoples that better respects their own understandings of themselves. As such, anthropologists should not only acknowledge the existence of and study alternative worldviews, but also adopt them when appropriate or necessary to more fully understand the metaphysical aspects of other cultures. In anthropology, for example, this can be accomplished by extending the rationale for and methodology of participant observation to worldview pluralism, thereby allowing for switching between worldviews when necessary to employ the most appropriate worldview for a subject under study. Specifically, if the subject has a metaphysical aspect, then a non-Western scientific worldview should be employed in studying that aspect, rather than simply dismissing it as unimportant or even non-existent. In archaeology, this approach is consistent with the goals of the growing Indigenous archaeology movement which asserts that archaeology ought to be performed "by, with, and for" Indigenous peoples (Atalay, 2006: p. 283; Colwell-Chanthaphonh et al., 2010: p. 229; Nicholas, 2001: p. 31; Silliman, 2010: p. 218, citing Nicholas, 2008).

"Scientific facts... are as much a product of the observer's human nature as they are of an underlying reality" (Little Bear, 2000: p. ix), so "to assert the legitimacy of different rationalities is not to advocate for relativism, but to acknowledge that there is no single epistemology that may lay exclusive claim to all domains of experience" (Tauber, 2009: p. 31). Real things can have both physical and metaphysical aspects, and both are amenable to reason, but only the physical is amenable to the direct empirical investigation that is the requirement of science. "The first task of the metaphysician, like the scientist, is to construct a hypothesis that accounts for the phenomena in question" (Ladyman, 2012: p. 33). "Metaphysics differs from science primarily in scope: Any scientist who... places his science in a wider setting, and presents a perspective in which his specialty is integrated with related fields, becomes to some extent a metaphysician" (Mitchell, 1946: pp. 274-275). Science has a useful role but it is too limited to be the exclusive vehicle in the pursuit of understanding. As such, the true seeker of knowledge should never limit him- or herself to being merely a scientist, because without an understanding of philosophy, the scientist is unguided, just as without an understanding of science, the philosopher is uninformed. For anthropologists and other social scientists, this means that without respect for alternative worldviews that recognize the possibility of metaphysical phenomenon and explanations, much of the world remains effectively closed to their understanding.

\section{Conflicts of Interest}

The authors declare no conflicts of interest regarding the publication of this paper.

\section{References}

Aikenhead, G. S. (1998). Many Students Cross Cultural Borders to Learn Science: Impli- 
cations for Teaching. Australian Science Teachers Journal, 44, 9-12.

Atalay, S. L. (2006). Indigenous Archaeology as Decolonizing Practice. American Indian Quarterly, 30, 280-310. https://doi.org/10.1353/aiq.2006.0015

Barth, F. (2002). An Anthropology of Knowledge. Current Anthropology, 43, 1-18. https://doi.org/10.1086/324131

Basalla, G. (1967). The Spread of Western Science. Science, 156, 611-622. https://doi.org/10.1126/science.156.3775.611

Berkes, F. (2012). Sacred Ecology. New York: Routledge. https://doi.org/10.4324/9780203123843

Cajete, G. (2000). Native Science: Natural Laws of Interdependence. Santa Fe, NM: Clear Light Publishers.

Chang, H. (2007). Scientific Progress: Beyond Foundationalism and Coherentism. In A. O'Hear (Ed.), Philosophy of Science (pp. 1-20). New York: Cambridge University Press. https://doi.org/10.1017/S1358246107000124

Chigeza, P. (2007). Indigenous Students in School Science. Teaching Science, 53, 10-15.

Cobern, W. W., \& Loving, C. C. (2001). Defining "Science" in a Multicultural World: Implications for Science Education. Science Education, 85, 50-67. https://doi.org/10.1002/1098-237X(200101)85:1<50::AID-SCE5>3.0.CO;2-G

Colwell-Chanthaphonh, C. et al. (2010). The Premise and Promise of Indigenous Archaeology. American Antiquity, 75, 228-238. https://doi.org/10.7183/0002-7316.75.2.228

Deloria, V. Jr. (1997). Red Earth, White Lies: Native Americans and the Myth of Scientific Fact. Golden, CO: Fulcrum Publishing.

Descola, P. (2013). Beyond Nature and Culture. Chicago, IL: The University of Chicago Press. https://doi.org/10.7208/chicago/9780226145006.001.0001

El-Hani, C. N., \& Bandeira, F. P. S. F. (2008). Valuing Indigenous Knowledge: To Call It "Science" Will Not Help. Cultural Studies of Science Education, 3, 751-779. https://doi.org/10.1007/s11422-008-9129-6

Fabian, J. (2012). Cultural Anthropology and the Question of Knowledge. Journal of the Royal Anthropological Institute, 18, 439-453. https://doi.org/10.1111/j.1467-9655.2012.01751.x

Feldhammer, L. (1967). Social Anthropology-Mechanized or Humanized? Anthropologica, New Series, 9, 29-35. https://doi.org/10.2307/25604742

Goduka, N. (2012). From Positivism to Indigenous Science: A Reflection on World Views, Paradigms, and Philosophical Assumptions. Africa Insight, 41, 123-137.

Good, D. L. (1989). Birds, Beads \& Bells: Remote Sensing of a Pawnee Sacred Bundle; Anthropological Series No. 15. Manhattan, NY: Kansas State Historical Society.

Gould, S. J. (1997). Non-Overlapping Magisteria. Natural History, 106, 16-22.

Hayward, J. W. (1997). Letters to Vanessa: On Love, Science, and Awareness in an Enchanted World. Boston, MA: Shambhala Publications.

Hess, D. J. (1995). Science and Technology in a Multicultural World: The Cultural Politics of Facts and Artifacts. New York: Columbia University Press. https://doi.org/10.7312/hess92728

Horsechief, E. J. (1988). Interview by T. A. Witty, Jr., \& D. L. Good in Pawnee, Oklahoma. Notes on File in Archaeology Laboratory, Topeka, KS: Kansas State Historical Society.

Howitt, R., \& Suchet-Pearson, S. (2003). Ontological Pluralism in Contested Cultural Landscapes. In M. Domosh, S. Pile, \& N. Thrift (Eds.), Handbook of Cultural Geogra- 
phy (pp. 557-569). Thousand Oaks, CA: Sage. https://doi.org/10.4135/9781848608252.n41

Irzik, G., \& Nola, R. (2009). Worldviews and Their Relation to Science. Science \& Education, 18, 729-745. https://doi.org/10.1007/s11191-007-9087-5

Johnson, J. T. (2012). Place-Based Learning and Knowing: Critical Pedagogies Grounded in Indigeneity. GeoJournal, 77, 829-836. https://doi.org/10.1007/s10708-010-9379-1

Johnson, J. T., \& Murton, B. (2007). Re/Placing Native Science: Indigenous Voices in Contemporary Constructions of Nature. Geographical Research, 45, 121-129. https://doi.org/10.1111/j.1745-5871.2007.00442.x

Kidwell, C. S. (1985). Native Knowledge in the Americas. Osiris, 1, 209-228. https://doi.org/10.1086/368646

Kuhn, T. S. (1962). The Structure of Scientific Revolutions. Chicago, IL: University of Chicago Press.

Ladyman, J. (2012). Science, Metaphysics and Method. Philosophical Studies, 160, 31-51. https://doi.org/10.1007/s11098-012-9910-y

Linton, R. (1923). Purification of the Sacred Bundles: A Ceremony of the Pawnee; Leaflet No. 7. Chicago, IL: Field Museum of Natural History.

Little Bear, L. (2000). Foreward. In G. Cajete (Ed.), Native Science: Natural Laws of Interdependence (pp. 9-12). Santa Fe, NM: Clear Light Publishers.

Marks, J. (2009). Why I Am Not a Scientist: Anthropology and Modern Knowledge. Berkeley, CA: University of California Press.

McGregor, D. (2003). Coming Full Circle: Indigenous Knowledge, Environment, and Our Future. American Indian Quarterly, 28, 385-410. https://doi.org/10.1353/aiq.2004.0101

McGregor, D. (2012). Traditional Knowledge: Considerations for Protecting Water in Ontario. The International Indigenous Policy Journal, 3, 1-21.

https://doi.org/10.18584/iipj.2012.3.3.11

Mendin, D. L., \& Bang, M. (2014). Who's Asking? Native Science, Western Science, and Science Education. Cambridge, MA: The MIT Press. https://doi.org/10.7551/mitpress/9755.001.0001

Mitchell, E. T. (1946). Metaphysics and Science. Philosophy of Science, 13, 274-280. https://doi.org/10.1086/286901

Morganti, M. (2013). Combining Science and Metaphysics: Contemporary Physics, Conceptual Revision and Common Sense. New York: St. Martin's Press. https://doi.org/10.1057/9781137002693

Munroe, E. A., Borden, L. L., Orr, A. M., Toney, D., \& Meader, J. (2013). Decolonizing Aboriginal Education in the 21st Century. McGill Journal of Education, 48, 317-337. https://doi.org/10.7202/1020974ar

Murie, J. R. (1914). Pawnee Indian Societies. American Museum of Natural History. Anthropological Papers, 11, 543-644.

Murie, J. R. (1981). Part I: The Skiri, Part II: The South Bands. In D. R. Parks (Ed.), Ceremonies of the Pawnee (pp. 1-497). Washington DC: Smithsonian Institution Press. https://doi.org/10.5479/si.00810223.27.1

Nader, L. (1996). Naked Science: Anthropological Inquiry into Boundaries, Power, and Knowledge. London: Routledge.

Nicholas, G. P. (2001). The Past and Future of Indigenous Archaeology: Global Challenges, North American Perspectives, Australian prospects. Australian Archaeology, 52, 29-40. https://doi.org/10.1080/03122417.2001.11681703 
Nicholas, G. P. (2008). Native Peoples and Archaeology. In D. M. Pearsall (Ed.), Encyclopedia of Archaeology, Volume 3 (pp. 1660-1669). New York: Elsevier. https://doi.org/10.1016/B978-012373962-9.00203-X

O’Meara, T. (1989). Anthropology as Empirical Science. American Anthropologist, 91, 354-369. https://doi.org/10.1525/aa.1989.91.2.02a00050

O’Meara, T. (1990). Anthropology as Metaphysics: Reply to Shore. American Anthropologist, New Series, 92, 751-753. https://doi.org/10.1525/aa.1990.92.3.02a00220

Olafson, F. A. (2001). Naturalism and the Human Condition: Against Scientism. New York: Routledge.

Parks, D. R. (1997). Bison Books Introduction. In G. A. Dorsey (Ed.), The Pawnee Mythology (pp. 5-27). Lincoln, NB: University of Nebraska Press.

Pierotti, R. (2011). Indigenous Knowledge, Ecology, and Evolutionary Biology. New York: Routledge. https://doi.org/10.4324/9780203847114

Pulido, L. (1998). The Sacredness of "Mother Earth": Spirituality, Activism, and Social Justice. Annals of the Association of American Geographers, 88, 719-723. https://doi.org/10.1111/0004-5608.00123

Rose, D. B. (1999). Indigenous Ecologies and an Ethic of Connection. In N. Low (Ed.), Global Ethics and Environment (pp. 175-187). New York: Routledge.

Ryan, A. (2008). Indigenous Knowledge in the Science Curriculum: Avoiding Neo-Colonialism. Cultural Studies of Science Education, 3, 663-683. https://doi.org/10.1007/s11422-007-9087-4

Ryan, J. C. (2011). Cultural Botany: Toward a Model of Transdisciplinary, Embodied, and Poetic Research into Plants. Nature and Culture, 6, 123-148.

https://doi.org/10.3167/nc.2011.060202

Sefadei, G. J., Hall, B. L., \& Rosenberg, G. (2000). Indigenous Knowledge in Global Contexts: Multiple Readings of Our World. Toronto: University of Toronto Press.

Silliman, S. W. (2010). The Value and Diversity of Indigenous Archaeology: A Response to McGhee. American Antiquity, 75, 217-220.

https://doi.org/10.7183/0002-7316.75.2.217

Simonds, V. W., \& Christopher, S. (2013). Adapting Western Research Methods to Indigenous Ways of Knowing. American Journal of Public Health, 103, 2185-2192. https://doi.org/10.2105/AJPH.2012.301157

Snively, G., \& Corsiglia, J. (2001). Rediscovering Indigenous Science: Implications for Science Education. Science Education, 85, 6-34.

https://doi.org/10.1002/1098-237X(200101)85:1<6::AID-SCE3>3.0.CO;2-R

Steeves, P. F. (2015). Decolonizing Indigenous Histories, Pleistocene Archaeology Sites of the Western Hemisphere. Doctoral Dissertation, Ann Arbor, MI: ProQuest.

Tauber, A. I. (2009). Science and the Quest for Meaning. Waco, TX: Baylor University Press.

Trigger, B. G. (1998). Archaeology and Epistemology: Dialoguing Across the Darwinian Chasm. American Journal of Archaeology, 102, 1-34. https://doi.org/10.2307/506135

Tsosie, R. (2015). Indigenous Peoples and Epistemic Justice: Science, Ethics, and Human Rights. Washington Law Review, 87, 1133-1201.

Turnbull, D. (2000). Masons, Tricksters and Cartographers: Makers of Knowledge and Space. New York: Routledge.

White Deer, G. (1998). Return of the Sacred: Spirituality and the Scientific Imperative. In D. S. Whitely (Ed.), Reader in Archaeological Theory: Post-Processual and Cognitive 
Approaches (pp. 331-337). New York: Routledge.

Wildcat, D. R. (2009). Red Alert: Saving the Planet with Indigenous Knowledge. Golden, CO: Fulcrum Publishing.

Wishart, D. J. (1979). The Dispossession of the Pawnee. Annals of the Association of American Geographers, 69, 382-401.

https://doi.org/10.1111/j.1467-8306.1979.tb01263.x 